\title{
Integration Model of Dynamic Inventory Replenishment and Pricing Based on Estimating Demand Substitution for PC Products
}

\author{
Jun-Jun Gao \\ Shanghai University \\ E-Mail: gaojunjun@shu.edu.cn \\ Tian-Tian Shi \\ Shanghai University \\ E-Mail: cheery@shu.edu.cn \\ Yue Liu \\ Shanghai University \\ E-Mail: yliu@staff.shu.edu.cn
}

\begin{abstract}
Motivated by the recent supply chain management practice of the Chinese PC industry, we examine the impact of demand forecasting and demand substitution estimation on inventory management and pricing with short selling seasons for a PC supply chain consisting of one retailer and two manufacturers. Based on PC products' demand characteristics, product life cycle (PLC) is incorporated into the traditional multiplication demand model and a multi-period dynamic inventory and pricing integrated decision model is developed. This model assumes that retailers always place an initial order at pre-season, and the order quantity would be split into multiple batches following the retailers' dynamic inventory replenishment requirements under the constraint that the sum of the split orders should be almost the same as the initial order. Meanwhile, the retailer would dynamically determine the selling price according to effective demand and demand forecasting per cycle, and the manufacturers decide the wholesale price and rebate depending upon the retailer's total order quantities. Finally, empirical analysis is given, and analysis results show that the model enjoys good feasibility and effectiveness, that can overcome the negative impact of high demand fluctuations on profits and service levels.
\end{abstract}

Keywords: Dynamic Inventory Decision, Dynamic Pricing, Demand Forecasting, Product Life Cycle, Demand Substitution 


\section{INTRODUCTION}

The perfect balance of supply and demand is a very difficult goal to achieve in a PC product supply chain because of short product life cycle, high technical upgrade, and diversification of demand, which limits the quick demand response and even risks loss of profit. Stimulated by the recent supply chain management practice of the Chinese PC industry, more and more PC enterprises are thinking of starting to transfer their focus from supply chain management to demand chain management, such as how Dell proposed consumer-centric supply chain management, demand-leading supply chain innovation management to provide more effective inventory control and appropriate pricing to achieve better coordination for the PC product supply chain.

The subject of this paper focuses on the joint decision of dynamic inventory and dynamic pricing with demand substitution and demand forecasting. There are some studies in such fields, but there is little existing work on considering multi-product and PC product issues, which are very practical in the PC product retail context.

Table 1 Stock-Out-Based Demand Substitution Type and Structure

\begin{tabular}{|c|c|c|c|c|c|}
\hline Substitution structure & & elated literature & $\begin{array}{c}\text { Bassok et al. } \\
(1999)\end{array}$ & $\begin{array}{c}\text { Eynan and } \\
\text { Fouque (2003) }\end{array}$ & $\begin{array}{c}\text { Nagarajan } \\
(2008) \\
\end{array}$ \\
\hline \multirow{3}{*}{ Substitution driver } & \multicolumn{2}{|c|}{ Customer-driven } & & & $\bullet$ \\
\hline & \multicolumn{2}{|c|}{ Supplier-driven } & $\bullet$ & & \\
\hline & \multicolumn{2}{|c|}{ Retailer-driven } & & $\bullet$ & \\
\hline \multirow{2}{*}{ Demand model } & \multicolumn{2}{|c|}{ Customer choice model } & & & \\
\hline & \multicolumn{2}{|c|}{ Probabilistic distribution } & $\bullet$ & $\bullet$ & $\bullet$ \\
\hline \multirow{2}{*}{ Substitution direction } & \multicolumn{2}{|r|}{ One-way } & $\bullet$ & $\bullet$ & $\bullet$ \\
\hline & \multicolumn{2}{|r|}{ Two-way } & & & \\
\hline \multirow{2}{*}{ Substitution attempt } & \multicolumn{2}{|c|}{ One-attempt } & $\bullet$ & $\bullet$ & $\bullet$ \\
\hline & \multicolumn{2}{|c|}{ Multi-attempt } & & & \\
\hline \multirow{3}{*}{ Number of substitutes } & \multirow{2}{*}{$\begin{array}{c}\text { One } \\
\text { product }\end{array}$} & For one product & & $\bullet$ & $\bullet$ \\
\hline & & $\begin{array}{c}\text { For } \\
\text { multi-products }\end{array}$ & $\bullet$ & & \\
\hline & \multicolumn{2}{|c|}{ Adjacent product } & & & \\
\hline \multirow{4}{*}{ Substitution rate } & & Full & $\bullet$ & & \\
\hline & \multirow{3}{*}{ Partial } & Constant & & & $\bullet$ \\
\hline & & Random & & $\bullet$ & \\
\hline & & estimation & & & \\
\hline
\end{tabular}


Since McGillivray and Silver (1978) explicitly introduced the concept of substitution for the first time in an inventory problem, a large amount of literature that studies inventory decisions with stock-out-based substitution appeared. We will not review this literature in detail (we refer the reader to Nagarajan and Rajagopalan (2008) for a recent review). In Table 1, we included three papers from this literature stream to demonstrate that researchers examined this problem from different perspectives such as with a full substitution rate (see Ignall and Veinott, 1969) or a partial substitution rate (Bassok et al., 1999). Similarly, researchers considered supplier-driven substitution (Bassok et al., 1999), retailer-driven substitution (Eynan and Fouque, 2003), and customer-driven substitution (Nagarajan and Rajagopalan, 2008). The majority of the papers in this literature focus on one-way substitution scenarios for which they characterize the optimal inventory policy to provide an algorithm to compute optimal inventory levels using a single-period inventory model. Early papers, such as the one by Bassok, Anupindi, and Akella (1999), showed non-correlated demand, whereas more recent papers also studied correlated demands (Ernst and Kamrad, 2006). As far as we know, adjacent substitution has not been considered in this literature stream. We establish a multi-period model with adjacent two-way substitution.

Thus, our paper contributes to research literatures in several ways: (a) generalizes single-period inventory model with a single product or two products to a multi-period joint-optimization model with multi-product under adjacent substitution structure, meanwhile adding the service level constraint for the joint-optimization model, (b) provides an insightful interpretation of adjacent substitution under an empirical setting when few papers provide empirical information about how to measure the substitution rate in the rapidly growing literatures on inventory management, (c) and introduces, based on PC products' demand characteristics, the product life cycle (PLC) into the traditional multiplication demand model and limited order flexibility into the joint-decision model. The results indicate that this model demonstrates good feasibility and effectiveness. Moreover, simulation results demonstrate that the product life cycle significantly impacts the profit and the integrated decision model can overcome the negative impact of high demand fluctuations on profits and service levels. 


\section{PROBLEM FORMULATION AND MODEL SOLUTION Assumptions and Notations}

We consider a supply chain with two manufacturers, HP PC (personal computer) and Lenovo PC, respectively and a single retailer, a leader in China's 3C (consumer appliances, computers and communications products) chain retailers of home appliances. The retailer places orders at pre-season, and the agreement order quantity is split into multiple batches following the retailers' weekly requirements. The sum of the split orders is no more than the multiplication of $\phi$ and the retailer's initial agreement order, in which $\phi$ is an order-flexible factor set by manufacturers.

Several variants of PC basic products are considered in the joint optimization model, supplied by HP and Lenovo, respectively. We denote the set of indices of all product variants by $\mathrm{V}=\{1, \ldots, \mathrm{N}\}$, and for simplicity we refer to a product variant $i$ $(i=1,2, \cdots, n)$, simply as "product $i$ ". Basic demand is defined as the demand of a product variant. The planning horizon for our model has $T$ time periods. The basic demand $D_{i t}$ of product $i$ in period $t(t=1,2, \cdots, T)$ follows a random distribution with price elasticity and product life cycle factor $L_{i t}$.

If product $i$ is out of stock on a given time period $t$, we assume that a certain fraction of consumers $\beta_{i j}$ will substitute from product $i$ to product $j$ (stock-out-based substitution). We assume that any unsatisfied demand after stock-out-based substitution would incur shortage cost. We also assume that the salvage value for each product is zero. We define effective demand $D_{i t}^{e}$ of product $i$ in period $t$ as the basic demand of a product plus any additional demand from other products due to stock-out-based substitution.

Consumers consider various attributes of a product (e.g., price, quality, and brand) when making a purchasing decision. We assume that the consumer assigns a weight $\varpi_{k}(k=1,2, \cdots, l)$ for each attribute; and makes its final purchasing decision based on the weighted average value of these attributes, which we denote $a_{i}=\sum_{k=1}^{l} a_{i}^{k} \cdot \varpi^{k}$. Without loss of generality, we rank products in increasing order according to their average attributes value $a_{i}$. Since consumers may not be willing to substitute a product with one that has a much higher or lower average value, we assume that a consumer is willing to substitute a product with only its adjacent products (i.e., products ranked immediately lower or higher; note that for the products with the highest and lowest average value, there is only one choice for a substitute product). Therefore, in case of a stock-out, the consumer will consider the immediate neighbors of the desired product and possibly substitute the product with the one with the closest attribute value. 
The retailer adopts a periodic review inventory replenishment policy for each product $i$ that remains constant through the planning horizon (with $T$ time periods); and sets the order-up to inventory level for each product in period $t$ at $S_{i t}=S_{i} \cdot L_{i t}$. She then places a replenishment order $Q_{i t}$ at the end of each period $t$. The order quantity $Q_{i t}$ equals the maximum inventory level $S_{i t}$ minus on-hand inventory level at the end of period $t$.

Let $C_{i}$ be the unit cost of production to the manufacturer, $P_{i t}$ be the sale price of product $i$ at period $t, h_{i}$ be the holding cost of product $i$ during $T$ periods, $B_{i}$ be the unit shortage cost, $W_{i}$ be the wholesale price, and $G$ be the rebate provided by manufacturers.

\section{Estimating Stock-Out-Based Substitution Rate}

Due to the technology and upgrade, the PLC (Product Life Cycle) of a PC product is slightly different from the PLC of other products. Its life cycle curve shows an symmetrical sigmoid shape. Based on PC products' demand characteristics, a product life cycle (PLC) coefficient is introduced into the traditional multiplication demand model to depict the asymmetrical sigmoid function of PC products' life cycle curves.

$$
D_{i t}=K_{i} P_{i t}^{\alpha_{i}} \cdot L \xi_{i}
$$

Where $K$ denotes the scale constant of the product, $\alpha$ denotes the price elasticity (sensitivity of demand derivation corresponding to the price fluctuation), $L_{t}$ denotes the PLC (Product Life Cycle) function of identical products of last season to derive the demand of current season, and $\xi$ denotes the random disturbance $\xi \sim N(\mu, \sigma)$.

From interviews with sales managers, we find out that, for the computers with similar configurations and prices, the influence on sales increments of the price reduction of $\mathrm{HP}$ is much more than that of Lenovo, that is to say, $\alpha_{1} \geq \alpha_{2}$. A demand forecasting model could use history data to estimate the coefficients in equation (1). First, select from the products of last season with similar brand and configuration as well as price. Second, analyze these products' sales data. The sales are the dynamic value of the life cycle function varying with time to forecast the demand of each period divided by the average sales revenue. Then, obtain a value of the current season. Last, estimate $K, \alpha$, and the mean value and standard deviation of $\xi$ in equation (1).

Note that the effective demand of $i$ is its basic demand sale $D_{i t}$ plus any 
demand from substitution demand $D_{i t}^{S B S}$ transferred from its neighborhood products that may substitute with product $i$ due to a stock-out. Since stock-out-based demand $D_{i t}^{S B S}$ cannot be larger than the leftover inventory of product $i$, we define effective demand as

$$
\begin{aligned}
D_{i t}{ }^{e} & =D_{i t}+D_{i t}^{S B S} \\
& =D_{i t}+\min \left[I_{i t}, \sum_{i \neq j} \beta_{i j} \cdot \max \left(0, D_{j t}-S_{j} \cdot L_{j t}\right)\right], i= \begin{cases}j+1 & \text { for } j=1 \\
j-1, j+1 & \text { for } 1<j<n \\
j-1 & \text { for } j=n\end{cases}
\end{aligned}
$$

From assumptions, we know that stock-out-based substitution rate $\beta_{i j}$ is based on the various attributes a consumer considers when making a purchasing decision and the values she assigns to these attributes. To estimate the stock-out-based substitution, a retailer can follow three steps.

(1) Select the number $k(k=1,2, \cdots, m)$ of attributes to consider and the corresponding attributes values $a_{i}^{k}$ (each attribute value can be easily translated to a ratio value from 0 to 1 , e.g., a price of $\$ 100$ for a product can be translated to 0.5 if $\$ 200$ is the sum of all prices of all products in the assortment).

(2) Estimate the weight $\varpi_{k}$ for each attribute of a product. Calculate the average attribute value $a_{i}$ for product $i$ as $a_{i}=\sum_{k=1}^{l} a_{i}^{k} \cdot \varpi_{k}$. Estimate the partial substitution coefficient $\mathrm{pr}_{j}$. As with the partial substitution coefficient, determining the appropriate number of attributes as well as the appropriate weight for each attribute must be left up to the retailer.

(3) According to our adjacent substitution assumption, the stock-out-based substitution rate $b_{i j}$ would be larger when the difference in the average attribute value between $i$ and $j$ is smaller. Thus, we define $\beta_{i j}$ as follows:

$$
\beta_{i j}= \begin{cases}\operatorname{Pr}_{j}, & \text { for } j=1, i=j+1 \\ {\left[1-\frac{\left|a_{j}-a_{i}\right|}{\left|a_{i+1}-a_{i-1}\right|}\right] \cdot \operatorname{Pr}_{j},} & \text { for } 1<j<n, i=j-1, j+1 \\ \operatorname{Pr}_{j}, & \text { for } j=n, i=j-1\end{cases}
$$

where $\operatorname{Pr}_{j}$ is the partial substation coefficient, which means that the consumer loyalty probability to $j$ is judged by the sales manager's experience. 


\section{Joint-Decision Model of Dynamic Inventory and Pricing}

We build demand forecasting and an inventory control integrated decision model upon the profit functions of the retailer and the manufacturer, respectively.

1. The profit function of retailer

The profit of the retailer is a combination of the sales profit as well as the rebate (when order quantity exceeds the agreement, the manufacturer offers the rebate to the retailer) minus the purchase cost, inventory holding cost, and shortage cost. The initial order quantity that the retailer makes before sales season equals the total quantity of forecasting of each period.

Note that the order quantity $Q_{i t}^{e}$ equals the maximum inventory level $S_{i t}$ minus the on-hand inventory level at the end of period $t$. That is

$$
Q_{i t}^{e}\left(S_{i}\right)=S_{i} \cdot L_{i t}-I_{i(t-1)}^{e}
$$

Further, the effective on-hand inventory level and stock-out quantities are

$$
\begin{gathered}
I_{i t}^{e}=\max \left(0, S_{i} \cdot L_{i t}-D_{i t}^{e}\right) \\
J_{i t}=\max \left(0, D_{i t}^{e}-S_{i} \cdot L_{i t}\right)
\end{gathered}
$$

Then, the total sales revenue of product $i$ during $T$ periods $S A_{i}^{e}$, the procurement cost $O C^{e}$, the shortage cost $H B$, and the inventory holding cost $H_{i t}^{e}$ are

$$
\begin{gathered}
S A_{i}^{e}=P_{i t} \cdot \sum_{t=1}^{T} \min \left[D_{i t}^{e}, S_{i} \cdot L_{i t}\right] \\
O C_{i}^{e}=W_{i} \cdot \sum_{t=1}^{T} Q_{i t}^{e} \\
H B_{i}=\sum_{t=1}^{T} B_{i} \cdot J_{i t} \\
H B_{i}^{e}=H B_{i}-B_{i} \cdot \sum_{i \neq j} \min \left[I_{j t}, \beta_{j i} \cdot\left(D_{i t}-S_{i} \cdot L_{i t}\right)\right] \\
H_{i}^{e}=h_{i} \cdot \frac{1}{T} \sum_{t=1}^{T}\left(\frac{S_{i} \cdot L_{i t}+I_{i t}^{e}}{2}\right)
\end{gathered}
$$

The manufacturer offers the retailer a rebate point $G_{i}^{e}$ unless the retailer's order quantity exceeds the agreement order; otherwise, there is no rebate: 


$$
G_{i}^{e}= \begin{cases}\gamma_{i} \cdot O C_{i}^{e}, & \sum_{t=1}^{T} Q_{i t}^{e} \geq Q_{i}, 0 \leq \gamma_{i} \leq 0.1 . \\ 0, & \sum_{t=1}^{T} Q_{i t}^{e}<Q_{i} .\end{cases}
$$

Then, the retailer's total revenue $T P R_{i}^{e}$ is as follows:

$$
T P R_{i}^{e}=S A_{i}^{e}-O C_{i}^{e}-H B_{i}^{e}-H_{i}^{e}+G_{i}^{e}
$$

The expected service level of the retailer can be defined as follows:

$$
E S L_{i}=1-\frac{\sum_{i=1}^{n} \sum_{t=1}^{T}\left\{J_{i t}-\sum_{i \neq j} \min \left[I_{j t}^{e}, \beta_{j i} \cdot J_{i t}\right]\right\}}{\sum_{i=1}^{n} \sum_{t=1}^{T} D_{i t}^{e}}
$$

2. The sales revenue, production, and rebate cost primarily comprise the profit function of manufacturers:

$$
T P M_{i}^{e}=\sum_{t=1}^{T}\left(W_{i}-C_{i}\right) Q_{i t}^{e}-G_{i}^{e}
$$

3. The dynamic inventory and pricing integration model

Suppose that the manufacturer is the leader and the retailer is the follower of this PC supply chain. First, we propose the manufacturer's profit optimization model. The objective function is the manufacturer's profit maximization and decision variables are wholesale price and rebate coefficient. The first constraint means that the rebate coefficient which manufacturer offers retailer is ranging from 0 to $10 \%$; the second constraint is the range of the manufacturer's acceptable wholesale price, for which $\underline{P}$ is the lower limit of the unit retail price and $C_{i}$ is the unit production cost, as follows:

$$
\begin{array}{ll} 
& \max _{\gamma_{i}, W_{i}} T P M_{i}^{e} \\
\text { s.t. } & 0 \leq \gamma_{i} \leq 0.1 \\
& C_{i} \leq W_{i} \leq \underline{P}
\end{array}
$$

Model Solution: We could use a numerical method to solve the manufacturer's optimal wholesale price and rebate coefficient. Searching the rebate coefficient in the closed interval $[0,0.1]$, as well as $W_{i}$ in the closed interval $\left[C_{i}, \underline{P}\right]$, we could finally find out the $\left(\gamma_{i}^{*}, W_{i}^{*}\right)$ that satisfies both constraints while realizing the maximization of 
profit.

Our objective is to maximize the retailer's total expected profit by choosing the optimal unit retail price per period $P_{i t}$ and optimal order-up-to inventory levels $S_{i}$ for each product, subject to the constraints of satisfying a minimum target service level, having a flexible order quantity, and accommodating the valuing range of decision variables. Defining $\Omega \in[0,1]^{m}$ as the $m$-dimensional space of $[0,1]$ intervals, we therefore can formulate the following nonlinear integer programming model to express the problem of jointly determining pricing and inventory replenishment:

$$
\begin{gathered}
\max _{P_{i t}, S_{i}} \operatorname{TPR}_{i}\left(\beta_{i j}\right)=\sum_{i=1}^{n} \sum_{t=1}^{T} \operatorname{TPR}_{i}\left(\beta_{i j}\right) \\
\text { s.t. } \quad E S L \geq T S L \\
\sum_{t=1}^{T} Q_{i t}^{e}\left(S_{i}\right) \geq \phi_{i} \cdot Q_{i} \\
S_{i}>0 \\
W_{i} \leq P_{i t} \leq \bar{P} \\
0 \leq \beta_{i j}<1, \beta_{i j} \text { derived from }(3) \\
\sum_{k=1}^{l} W_{k}=1,\left(\varpi_{1}, \varpi_{2}, \ldots, \varpi_{m}\right) \in \Omega
\end{gathered}
$$

Model Solution: We also could use the numerical method to solve the retailer's optimal inventory level and retail price. Searching $P_{i t}$ in the closed interval $\left[W_{i}, \bar{P}\right.$ ], and $S_{i}$ in the closed interval $\left(0, Q_{i}\right]$, we finally find out the $\left(S_{i}^{*}, P_{i t}^{*}\right)$ that satisfies all constraints while realizing the maximization of the retailer's profit.

\section{Solution for this Stackelberg Game Model:}

Step 1: Based on (16), the manufacturer determines an initial rebate coefficient and a wholesale price $\left(\gamma_{i}^{1}, W_{i}^{1}\right)$ which the superscript represents the optimum decision value to the first calculation.

Step 2: After learning the rebate coefficient and wholesale price, based on (17), the retailer could find the optimum $\left(S_{i}^{1}, P_{i t}^{1}\right)$. 
Step 3: After acquiring the latest replenishment and sales price, based on (16) again, the manufacturer could find out the optimum $\left(\gamma_{i}^{2}, W_{i}^{2}\right)$.

Step 4: Return to Step 2.

The computation stops until the sequential calculation reaches a balanced error no less than a given constant $\varepsilon$. Then, we obtain the optimal solution $\left(\gamma_{i}^{*}, W_{i}^{*}, S_{i}^{*}, P_{i t}^{*}\right)$. Finally, we could obtain the maximal profit of the members of the supply chain as well as the entire supply chain.

\section{APPILICATION STUDY OF MODEL}

\section{Parameter Estimation}

We take logs of both sides of equation (1) in order to use Eviews to estimate the coefficients by the regression analysis method. The demand function is transferred to a multi-element linear model as follows:

$$
\operatorname{Ln}\left(D_{i t}\right)=\operatorname{Ln}\left(K_{i}\right)-\alpha_{i} \operatorname{Ln}\left(P_{i t}\right)+\operatorname{Ln}\left(L_{i t}\right)+\operatorname{Ln}\left(\xi_{i}\right)
$$

The data of this model are sourced from a chain retailer of home appliances in Shanghai. Our test sample consists of PC sales data during one year and three months (62 weeks in all). We chose products from HP and Lenovo. Product 1 and product 3 belong to the HP brand; product 2 and product 4 belong to the Lenovo brand. Based on the basic sales data of all products, see Table 3, we use Eviews's multi-element linear regression to estimate the demand model parameters and other parameters shown in Table 2.

Table 2 Value of Parameters in the Model

\begin{tabular}{cccccc}
\hline & Parameter & Product 1 & Product 2 & Product 3 & Product 4 \\
\hline \multirow{2}{*}{ Demand } & $\boldsymbol{K}_{i}$ & 16366.63 & 595.8566 & 20889.46 & 483.9589 \\
\cline { 2 - 6 } & $\alpha_{i}$ & 0.79 & 0.50 & 0.80 & 0.42 \\
\hline \multirow{2}{*}{ Cost } & $W_{i}$ & $0.80^{*} \overline{P_{1}}$ & $0.85^{*} \overline{P_{2}}$ & $0.80^{*} \overline{P_{1}}$ & $0.85^{*} \overline{P_{2}}$ \\
\cline { 2 - 6 } & $C_{i}$ & $0.80^{*} W_{1}$ & $0.85^{*} W_{2}$ & $0.80^{*} W_{1}$ & $0.85^{*} W_{2}$ \\
\hline \multirow{2}{*}{ Constraint } & $\boldsymbol{h}_{\boldsymbol{i}}$ & $0.20^{*} \overline{P_{1}}$ & $0.15^{*} \overline{P_{2}}$ & $0.20^{*} \overline{P_{1}}$ & $0.15^{*} \overline{\boldsymbol{P}_{2}}$ \\
\cline { 2 - 6 } & $\boldsymbol{B}_{i}$ & 10000 & 10000 & 10000 & 10000 \\
\hline \multirow{2}{*}{ Sub-rate } & $T S L_{i}$ & 0.90 & 0.85 & 0.90 & 0.85 \\
\hline
\end{tabular}


Table 2 Value of Parameters in the Model (Continued)

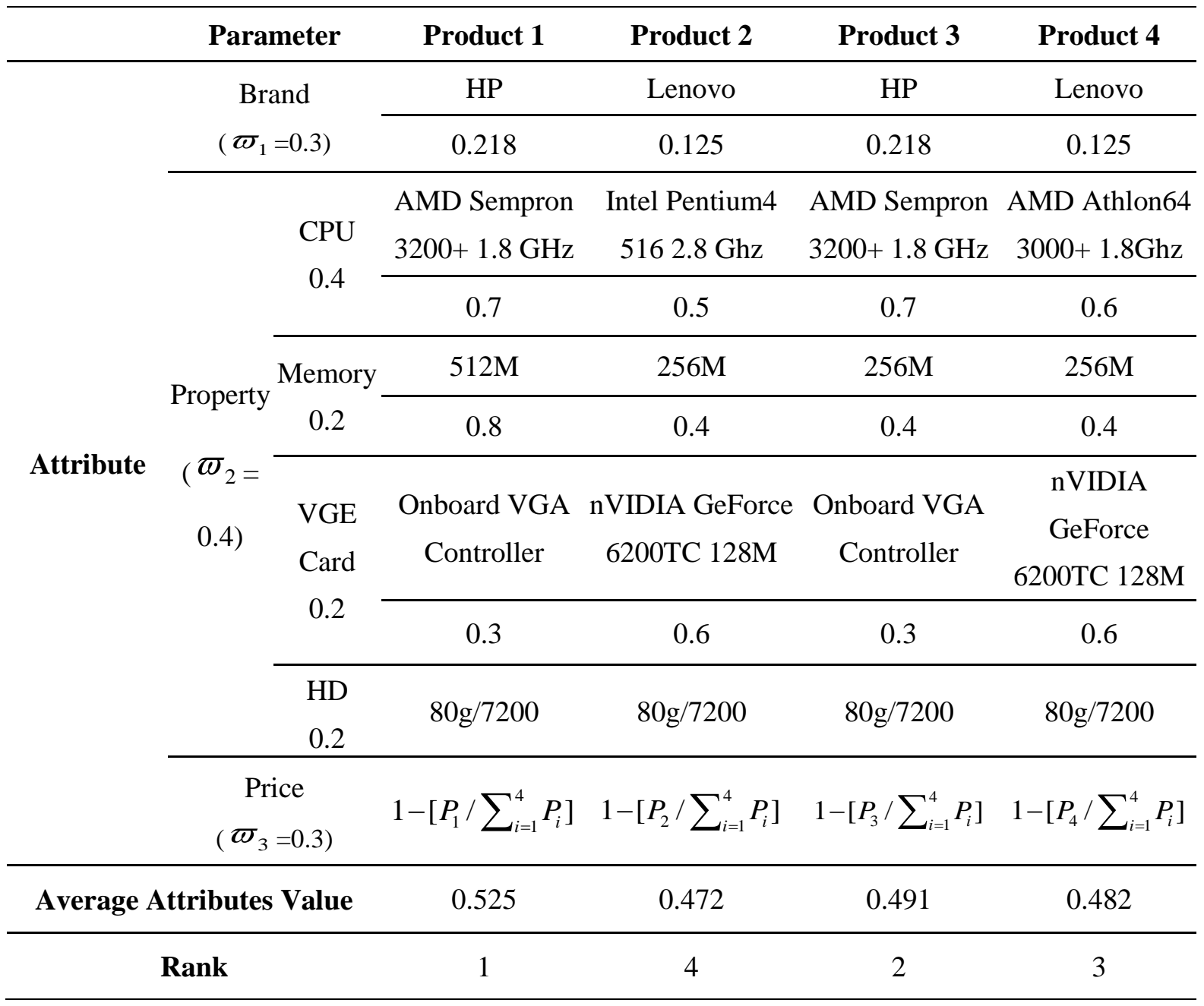

We obtain the products' ranks by the attribute value and corresponding weight. From the brand loyalty, which referred to ZOC's survey data of 2005, we find out the substitution rate of the PC product. ZOC divided the attributes into brand, property, and price, and the property is further segmented into CPU, memory, VGE card, and HD.

Table 3 Weekly Sales Data from September to December

\begin{tabular}{cccccccccccccccccc}
\hline $\begin{array}{c}\text { The } \\
\text { Week }\end{array}$ & $\mathbf{1}$ & $\mathbf{2}$ & $\mathbf{3}$ & $\mathbf{4}$ & $\mathbf{5}$ & $\mathbf{6}$ & $\mathbf{7}$ & $\mathbf{8}$ & $\mathbf{9}$ & $\mathbf{1 0}$ & $\mathbf{1 1}$ & $\mathbf{1 2}$ & $\mathbf{1 3}$ & $\mathbf{1 4}$ & $\mathbf{1 5}$ & $\mathbf{1 6}$ & $\mathbf{1 7}$ \\
\hline$D_{1}$ & 2 & 3 & 6 & 12 & 25 & 40 & 50 & 60 & 62 & 50 & 35 & 24 & 12 & 10 & 5 & 3 & 3 \\
\hline$D_{2}$ & 10 & 12 & 14 & 19 & 26 & 30 & 40 & 46 & 55 & 35 & 20 & 10 & 6 & 4 & 2 & 2 & 2 \\
\hline$D_{3}$ & 3 & 6 & 7 & 8 & 14 & 17 & 24 & 27 & 25 & 35 & 40 & 23 & 12 & 8 & 5 & 2 & 2 \\
\hline$D_{4}$ & 2 & 2 & 3 & 5 & 9 & 14 & 18 & 22 & 26 & 35 & 20 & 15 & 10 & 6 & 4 & 3 & 1 \\
\hline
\end{tabular}




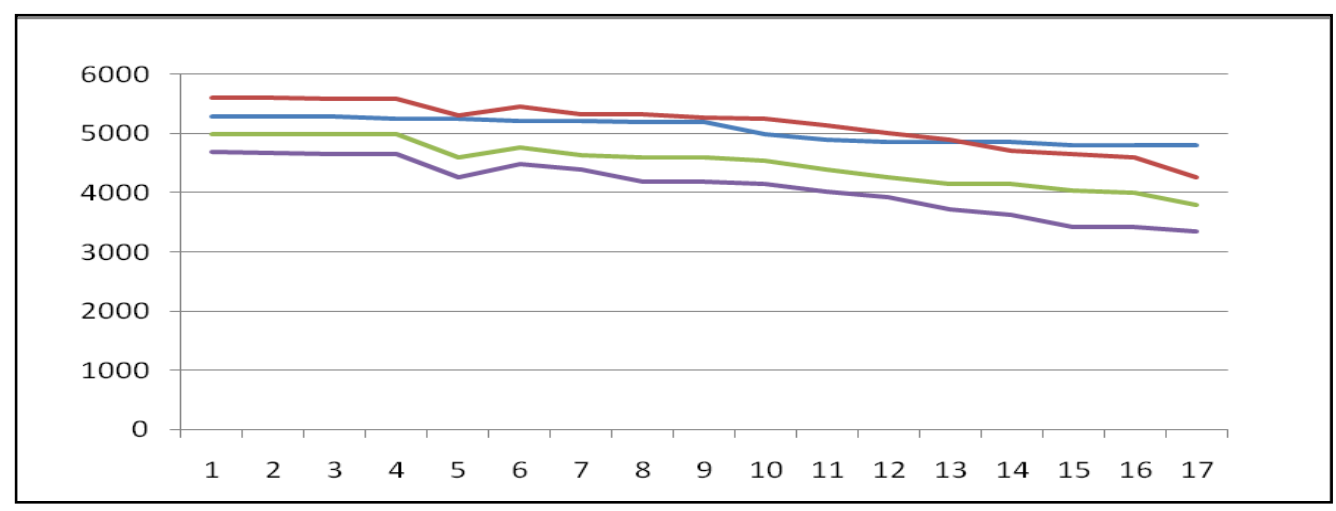

Figure 1 Price Fluctuation Curves of Four Products of HP and Lenovo

Figure 2 and Figure 3 show that the fitted demand curve tracks demand better; and the goodness-of-fit of the four products reaches $R S_{1}=0.8947, R S_{2}=0.9593$, $R S_{3}=0.8998$, and $R S_{4}=0.7136$, respectively.

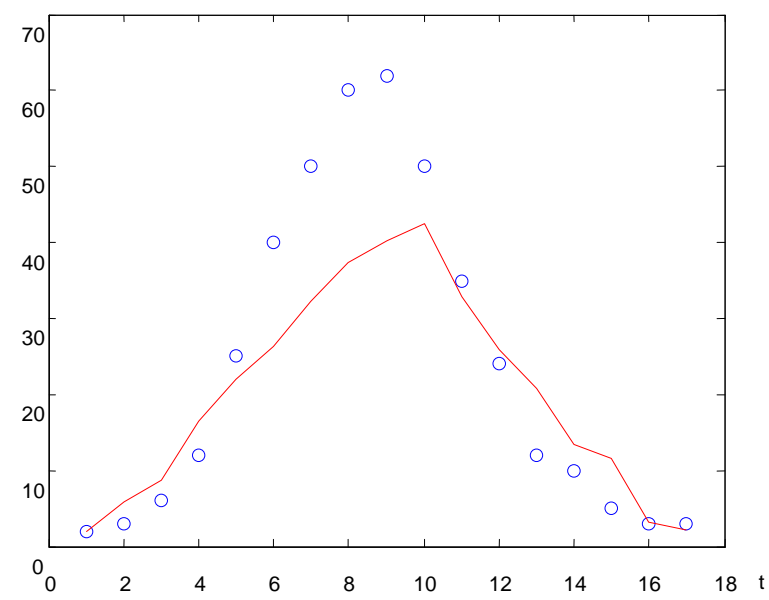

Figure 2 Demand Fitting Curve of Pro-1

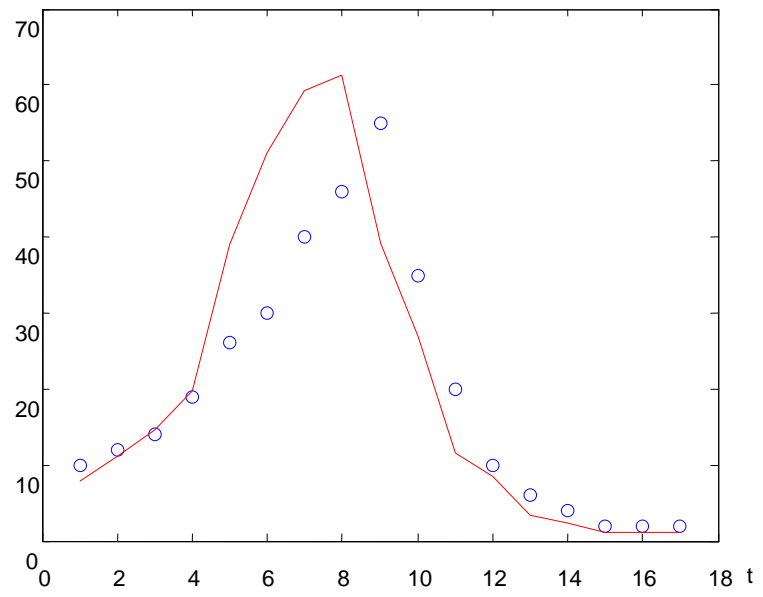

Figure 3 Demand Fitting Curve of Pro-2

Note: The circles represent the original demand data, and the straight line represents the fitted demand curve. 


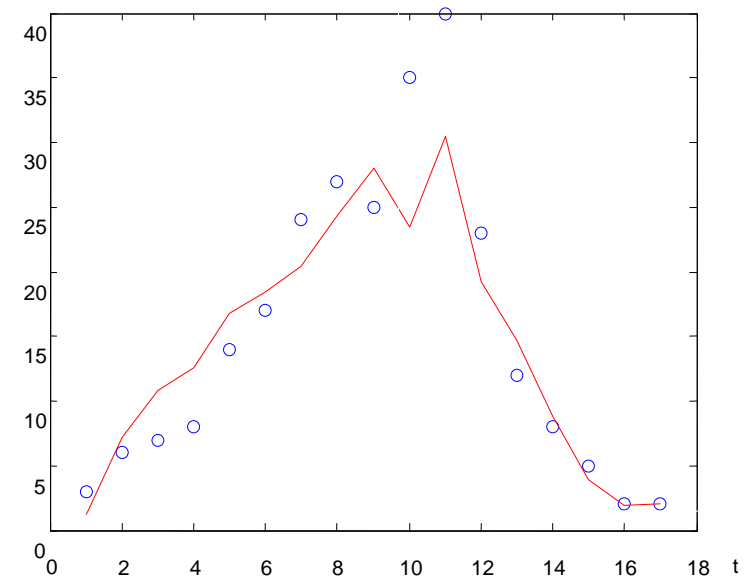

Figure 4 Demand Fitting Curve of Pro-3

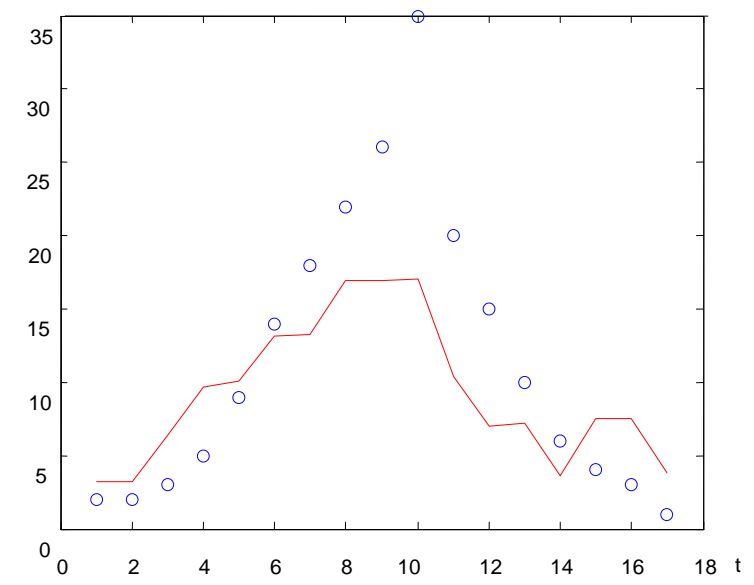

Figure 5 Demand Fitting Curve of Pro-4

\section{Application of Model}

Figures 6-9 show that the trends of markdown of both HP and Lenovo are unanimous. Under ORI mode, the sales price is identical with the price under ORI2 mode; therefore, the ORI line and ORI2 line are overlapped in figures 6-9. Under STA2 strategy, the price of product 1 is apparently higher than the other three products'. Because there is substitution between product 1 and product 2 that improves the combination of these two products, when both inventory level and sales of product 1 happen to reduce, the supply chain of HP always performs better. Product 2 meets the majority part of the shortage of product 1; in consequence, the order-up-to-inventory level of product 2 surges under STA2 strategy. Meanwhile, the increase of sales leads to the reduction of price. There is no significant change in the maximum inventory level and sales of product 3 so that price changing under STA 
and STA2 strategies is similar.

Though there is also no significant change of price, the demand of product 4 reached peak during the $10^{\text {th }}$ week, leading to the demand's exceeding the supply under STA strategy. That is to say, the shortage of the product produced a small price ascent during the $10^{\text {th }}$ week.

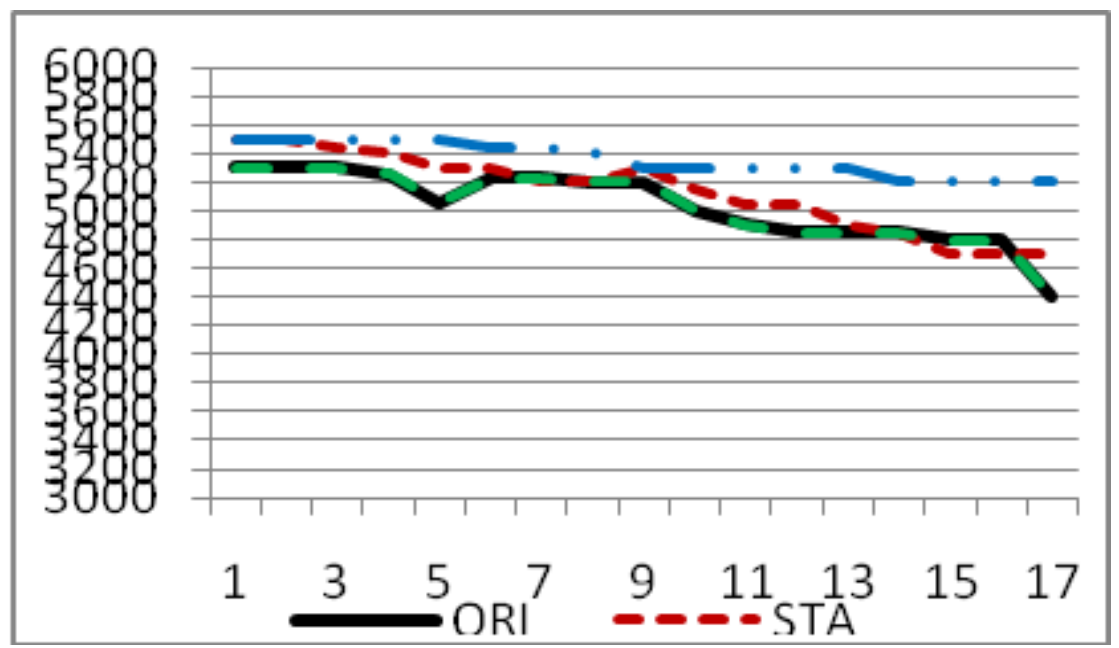

Figure 6 Sales Price Fluctuation of Pro-1

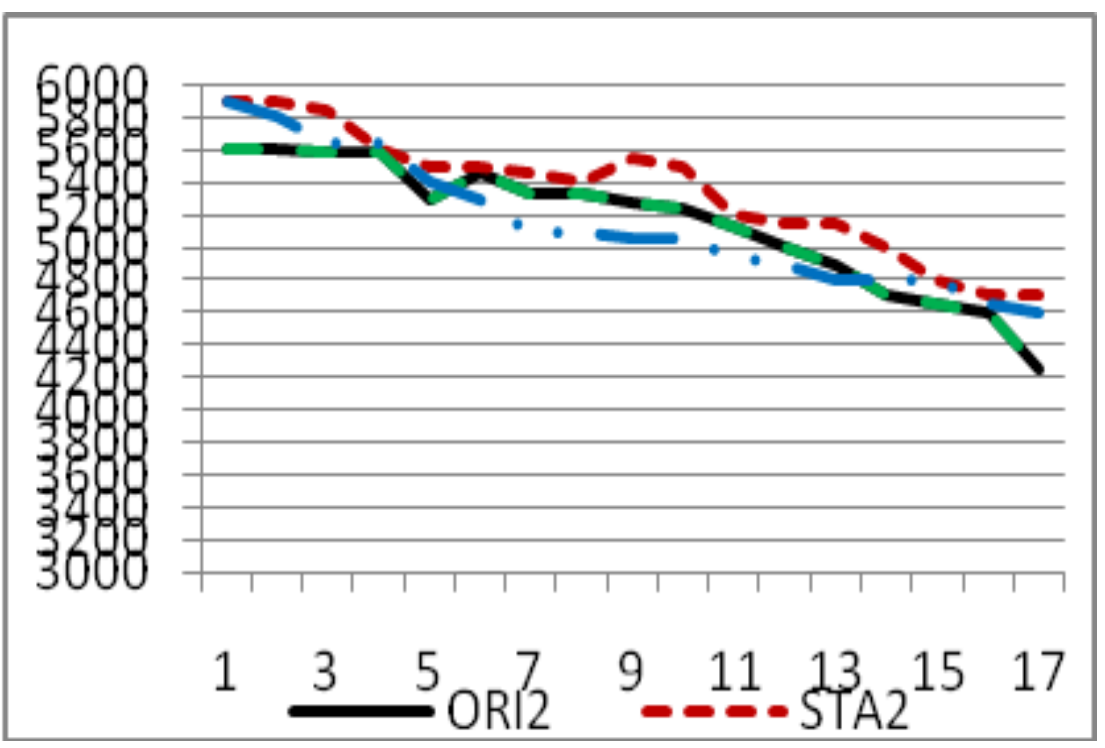

Figure 7 Sales Price Fluctuation of Pro-3 


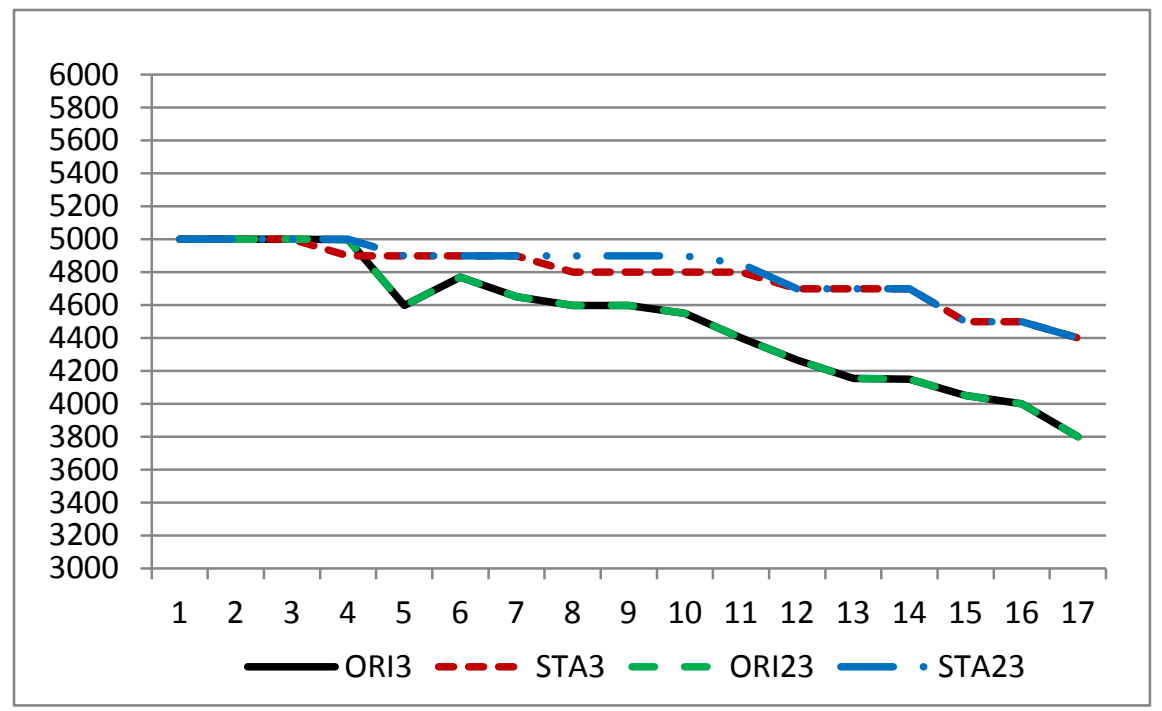

Figure 8 Sales Price Fluctuation of Pro-2

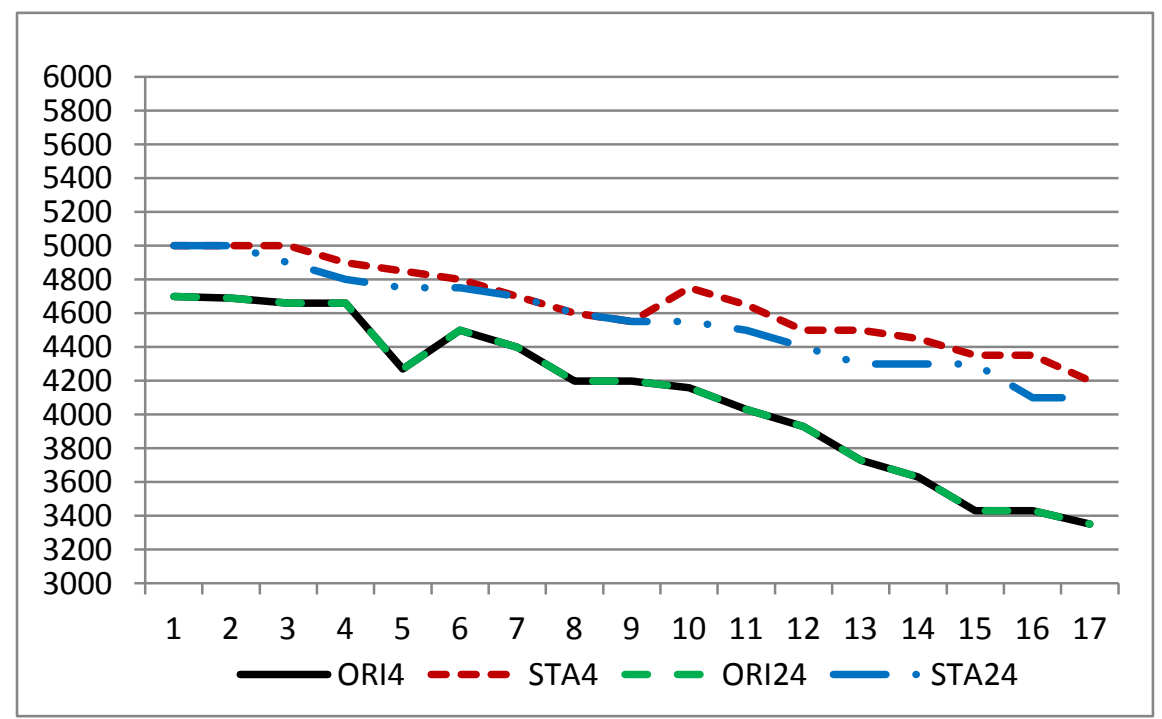

Figure 9 Sales Price Fluctuation of Pro-4

\section{- Supply Chain Profit}

On one hand, the master game STA2 strategy considering substitution acquires a better profit in terms of the whole profit of the supply chain because of the quick replenishment of other products to satisfy the shortage, which lowers the shortage cost; on the other hand, under our numerical method, the final result realizes the maximal profit of the whole supply chain; HP and Lenovo have a $2.25 \%$ and $0.38 \%$ improvement of supply chain profit, respectively. 
- Service Level

The average supply chain service level of HP increases by $3.67 \%$ from ORI to ORI2 and $2.52 \%$ from STA to STA2. The average inventory level of HP stays at 21 because that supply chain is in a balanced position; manufacturers and retailers reach a balance between supply and demand. The average supply chain service level of Lenovo also increases. The average inventory level of Lenovo sees a higher fluctuation under STA because of the shortage under ORI-while the increase of maximum inventory level makes up the shortage. Furthermore, considering the substitution, ORI2 and STA2 could achieve a higher profit under a lower average inventory level.

\section{Simulation Analysis}

- Product Life Cycle Sensitivity Analysis

The PLC of PC products exerts a significant impact on demand. We will analyze the sensitivity of PLC. Figures 10-11 show that B1 represents the original PLC function of the model, which has a similar brand and configuration and could effectively forecast the demand of product 1 . The data of R1 and R2 also come from the last sales season, but the attributes are very different from product 1's.

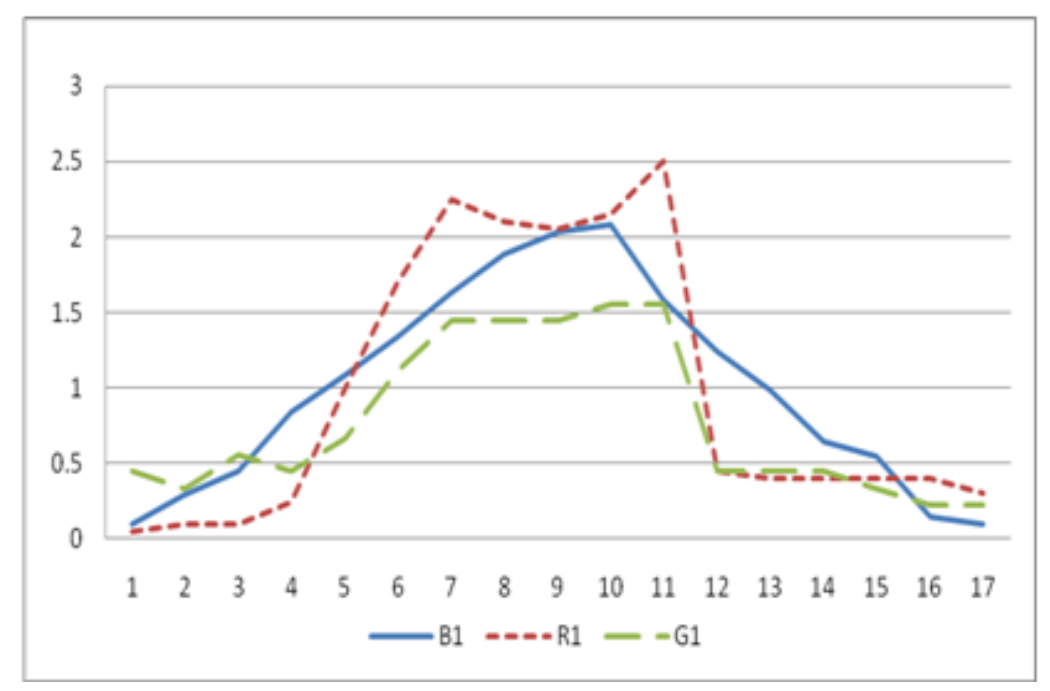

Figure 10 PLC Curves of 3 Products, HP 


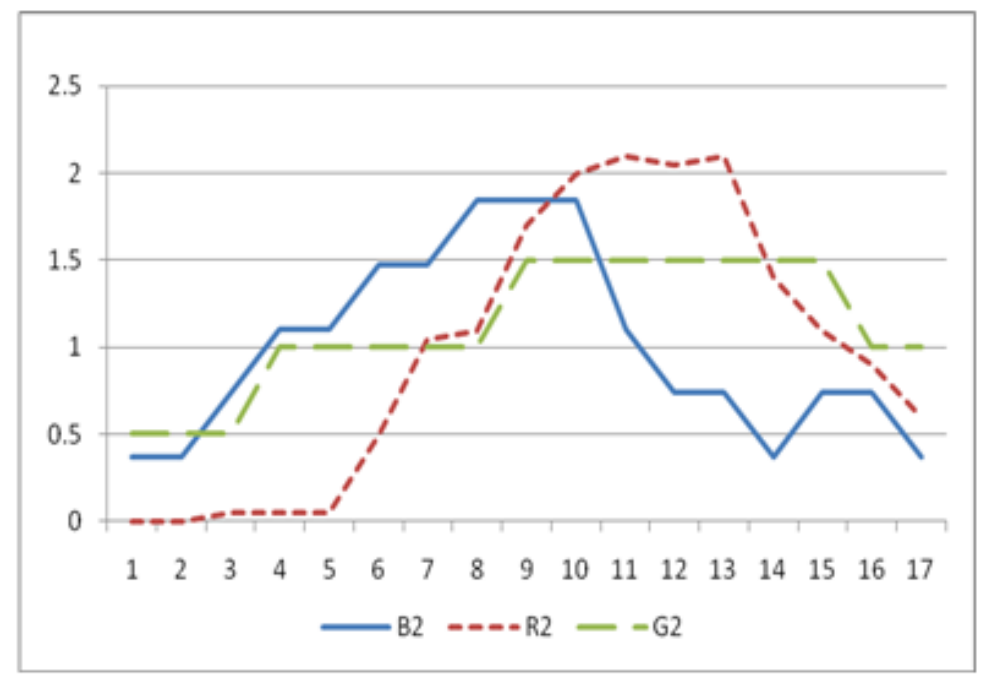

Figure 11 PLC Curves of 3 Products, Lenovo

Table 4 makes a comparison of ORI and STA. From the vertical review, whichever strategies were employed, we could achieve a better profit than in $\mathrm{R} 1$ and G1 if we choose B1 as the PLC function. Furthermore, we find that PLC has appreciable impact on demand, profit, and service level, so if we use a suitable PLC function, we could achieve a better demand forecast. Therefore, only through the reasonable judgment of the market manager on product familiarity and experience can we choose a better PLC function or else a worse profit. From horizontal review, for the original strategy and Stackelberg game, no matter how the PLC function changes, table 4 shows that the Stackelberg game is always achieving a better profit and the maximum goodness-of-fit of $34.46 \%$. Therefore, the Stackelberg game model is doing well.

Table 4 Sensitivity Analysis of PCL $L_{t}$ on Demand and Profit

\begin{tabular}{|c|c|c|c|c|c|c|}
\hline \multirow[b]{2}{*}{$L_{i t}$} & \multirow[b]{2}{*}{ Product } & \multicolumn{2}{|c|}{$D_{i t}$} & \multicolumn{3}{|c|}{$T P R_{i}$} \\
\hline & & ORI & STA & ORI & STA & (2) $-(1) /(2)$ \\
\hline B1 & \multirow{3}{*}{ Pro. 1} & 353 & 309 & $3.534 \mathrm{e}+005$ & $4.608 e+005$ & $13.13 \%$ \\
\hline $\mathbf{R} \mathbf{1}$ & & 377 & 297 & $3.4525 \mathrm{e}+005$ & $4.4043 \mathrm{e}+005$ & $21.61 \%$ \\
\hline G1 & & 275 & 238 & $2.6080 \mathrm{e}+005$ & $3.1461 \mathrm{e}+005$ & $17.10 \%$ \\
\hline B2 & \multirow{3}{*}{ Pro. 2} & 188 & 171 & $1.0567 e+005$ & $1.6123 e+005$ & $34.46 \%$ \\
\hline $\mathbf{R 2}$ & & 193 & 159 & $7.0538 \mathrm{e}+004$ & $1.5660 \mathrm{e}+005$ & $54.95 \%$ \\
\hline G2 & & 218 & 191 & $9.1894 \mathrm{e}+004$ & $1.9960 \mathrm{e}+005$ & $53.96 \%$ \\
\hline
\end{tabular}




\section{- Partial Substation Coefficient Sensitivity Analyses}

The substitution of products occurs when a certain product is out of stock. Both the substitution quantity and substitution pattern are highly related with the substitution rate Pr. We will study the effect of a partial substitution rate on profit and service level. Pr possesses two characteristics: (1) Pr is connected with brand loyalty, and the higher the brand loyalty, the smaller the $\operatorname{Pr}$. (2) $\operatorname{Pr}$ and attributes value decide $\beta_{i j}$ together, and $\operatorname{Pr}$ reacts upon product demand through $\beta_{i j}$, then reacts upon profit.

We analyze the sensitivity of $\operatorname{Pr}$ in the following 4 conditions:

(1) HP's and Lenovo's Prs are increasing in equal fluctuation ranges at the same time, (2) HP's and Lenovo's $\operatorname{Pr}$ are decreasing in equal fluctuation range at the same time, (3) HP's $\operatorname{Pr}$ is increasing while Lenovo's $\operatorname{Pr}$ is decreasing, (4) HP's $\operatorname{Pr}$ is decreasing while Lenovo's Pr is increasing.

Table 5 shows that when HP's and Lenovo's Prs are increasing or decreasing at the same time, HP's and Lenovo's profits of the whole supply chain are correspondingly increasing or decreasing. This is because the change of $\operatorname{Pr}$ leads to the change of $\beta_{i j}$ which, regardless of increase or decrease, will directly influence the change of demand in an identical trend. When HP's Pr changes in an opposite trend with Lenovo's $\operatorname{Pr}$, one side will achieve a lower profit (decreasing $\operatorname{Pr}$ ). This is because if HP's $\operatorname{Pr}$ is increasing, it leads to the increment of substitution demand as well as profit. However, the decreasing of Lenovo's $\operatorname{Pr}$ introduces more substitution coming from HP. If Lenovo appears to be out of stock without effective replenishment, there will be more profit for HP and less for Lenovo.

\section{CONCLUSIONS}

This paper established a Stackelberg game model for the PC industry with two manufacturers and one retailer. Under the assumption that the two manufacturers offer a series of products with substitution and identical configuration, Product Life Cycle (PLC) is effectively introduced into the traditional multiplication demand model, and a multi-period dynamic inventory and pricing integrated decision model of a PC product is established based on demand forecasting. At the same time, a retailer would determine the optimal inventory level and the optimal sales price during each period according to the model, and the manufacturers decide the wholesale price and rebate depending upon the total amount of the retailer's order. We apply this model to a large home appliance retailer. We found that this model is entitled with better feasibility and 
application effect. Under STA2 strategy, both the whole supply chain profit and service level are the most optimal strategy, which means that it is significant and essential to incorporate the substitution of demand into inventory and pricing decision. We also find that the estimation of PLC and brand loyalty influence the profit and service level greatly. The future study could extend to incorporate PLC learning, brand loyalty, and other marketing problems into supply chain management research.

Table 5 Sensitivity Analysis of Partial Substitution Coefficient on Supply Chain Profit

\begin{tabular}{|c|c|c|c|c|c|c|}
\hline \multirow{2}{*}{ Range } & \multirow{2}{*}{$\begin{array}{c}\text { Partial } \\
\text { Substitution } \\
\text { Coefficient }\end{array}$} & \multirow{2}{*}{ Brand } & \multicolumn{4}{|c|}{ Profit (unit: RMB) } \\
\hline & & & ORI & ORI2 & STA & STA2 \\
\hline \multirow{2}{*}{ No fluctuation } & 0.782 & HP & $1,286,400$ & $1,436,200$ & $1,707,100$ & $1,746,400$ \\
\hline & 0.875 & Lenovo & 556,700 & 587,250 & 899,800 & 903,200 \\
\hline \multirow{2}{*}{$\begin{array}{l}\text { Increase by } 10 \% \\
\text { both }\end{array}$} & 0.8602 & HP & $1,298,700$ & $1,435,300$ & $1,709,900$ & $1,751,700$ \\
\hline & 0.9625 & Lenovo & 566,700 & 595,300 & 910,800 & 911,100 \\
\hline \multirow{2}{*}{$\begin{array}{l}\text { Decrease by } 10 \% \\
\text { both }\end{array}$} & 0.7038 & $\mathrm{HP}$ & $1,186,400$ & $1,339,200$ & $1,615,200$ & $1,633,700$ \\
\hline & 0.7875 & Lenovo & 469,800 & 501,100 & 800,400 & 803,200 \\
\hline \multirow{2}{*}{$\begin{array}{l}\text { HP increase by } \\
10 \% \text {, Lenovo } \\
\text { decrease by } 10 \%\end{array}$} & 0.8602 & HP & $1,290,200$ & $1,446,800$ & $1,711,500$ & $1,750,000$ \\
\hline & 0.7875 & Lenovo & 452,300 & 500,200 & 799,900 & 768,500 \\
\hline \multirow{2}{*}{$\begin{array}{l}\text { HP decrease by } \\
10 \% \text {, Lenovo } \\
\text { increase by } 10 \%\end{array}$} & 0.7038 & HP & $1,154,300$ & $1,237,200$ & $1,595,200$ & $1,603,700$ \\
\hline & 0.9625 & Lenovo & 586,700 & 621,500 & 933,800 & 953,100 \\
\hline
\end{tabular}

\section{REFERENCES}

Bassok, Y., Anupindi, R., and Akella, R. (1999). Single-period multi-product inventory models with substitution. Operations Research, 47(4), 632-642.

Ernst, R. and Kamrad, B. (2006). Estimating demand by using sales information: inaccuracies encountered. European Journal of Operational Research, 174(2), 675-688. 
Eynan, A. and Fouque, T. (2003). Capturing the risk-pooling effect through demand reshape. Management Science, 49(6), 704-717.

Ignall, E. and Veinott, Jr. A. (1969). Optimality of myopic inventory policies for several substitution products. Management Science, 15(5), 284-304.

McGillivray, A. R. and Silver, E. A. (1978). Some Concepts for Inventory Control under Substitutable Demand. INFOR, 16(1), 47-63.

Nagarajan, M. and Rajagopalan, S. (2008). Inventory Models for Substitutable Products: Optimal Policies and Heuristics. Management Science, 54(8), 1453-1466. 